\title{
Rapid Enrichment and Detection of Extracellular Vesicles Enabled by CuS-Enclosed Microgels
}

Qiaoshi Jiang, ${ }^{1,+}$ Yang Liu, ${ }^{1,+}$ Linlin Wang, ${ }^{2}$ Gary Brent Adkins, ${ }^{2}$ Wenwan Zhong, ${ }^{1,2, *}$

${ }^{1}$ Environmental Toxicology Graduate Program; ${ }^{2}$ Department of Chemistry, University of California-Riverside, Riverside, CA 92521

\section{Supporting Information}

\section{Table of Contents}

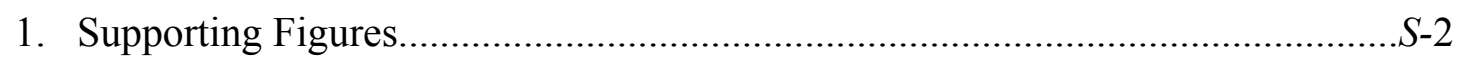

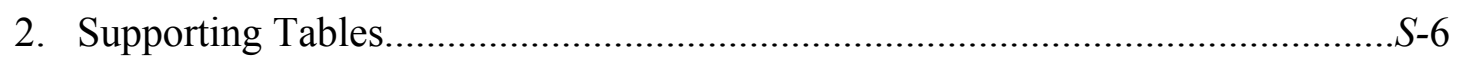




\section{Supporting Figures}

Figure S1. a) TEM image of $100 \mathrm{~nm} \mathrm{CuS-MG;} \mathrm{b)} \mathrm{XPS} \mathrm{(S} \mathrm{2p)} \mathrm{spectrum} \mathrm{of} \mathrm{three} \mathrm{sized}$ $\mathrm{CuS}-\mathrm{MG}$ and $500 \mathrm{~nm}$ original MG; c) Zeta potential of original $\mathrm{MG}$ and $\mathrm{CuS}-\mathrm{MG}$.
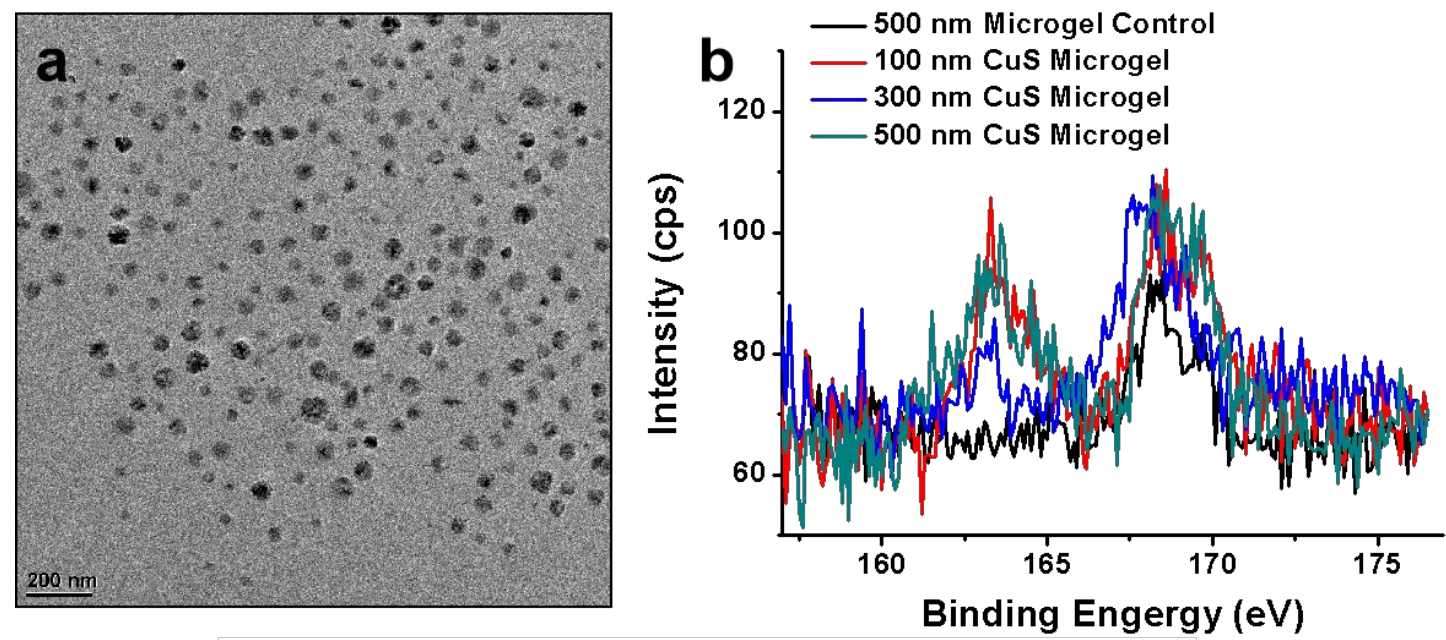

\begin{tabular}{|c|c|}
\hline Cype & Zeta Potential (mV) \\
\hline original microgel & $-19.28 \pm 2.86$ \\
\hline CuS microgel & $-23.59 \pm 2.03$ \\
\hline
\end{tabular}

Figure S2. Continuous monitoring of CL emission from $\mathrm{Cu}^{2+}$ released by acid digestion from microgels of different concentration. CL reached plateau at various time points, and thus the signal was monitored for $120 \mathrm{~s}$ and the data point collected at $120 \mathrm{~s}$ was used as the final signal.

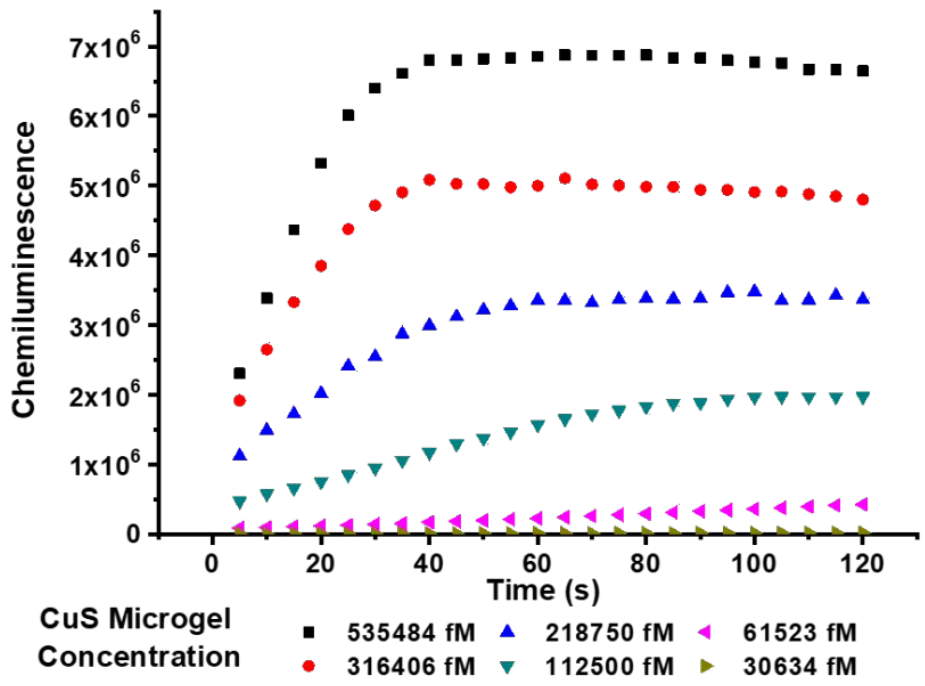


Figure S3. a) Optimization of acid digestion time of $\mathrm{CuS}-\mathrm{MG}$; b) passing rate ( 0.45 $\mu \mathrm{m}$ filter membrane) of MGs with $300 \mathrm{~nm}$ and $500 \mathrm{~nm}$ diameter; c) optimization of streptavidin concentration for $\mathrm{CuS}-\mathrm{MG}$ labelling. $[\mathrm{CuS}-\mathrm{MG}]=5 \times 10^{9}$ particles $/ \mathrm{ml}$.
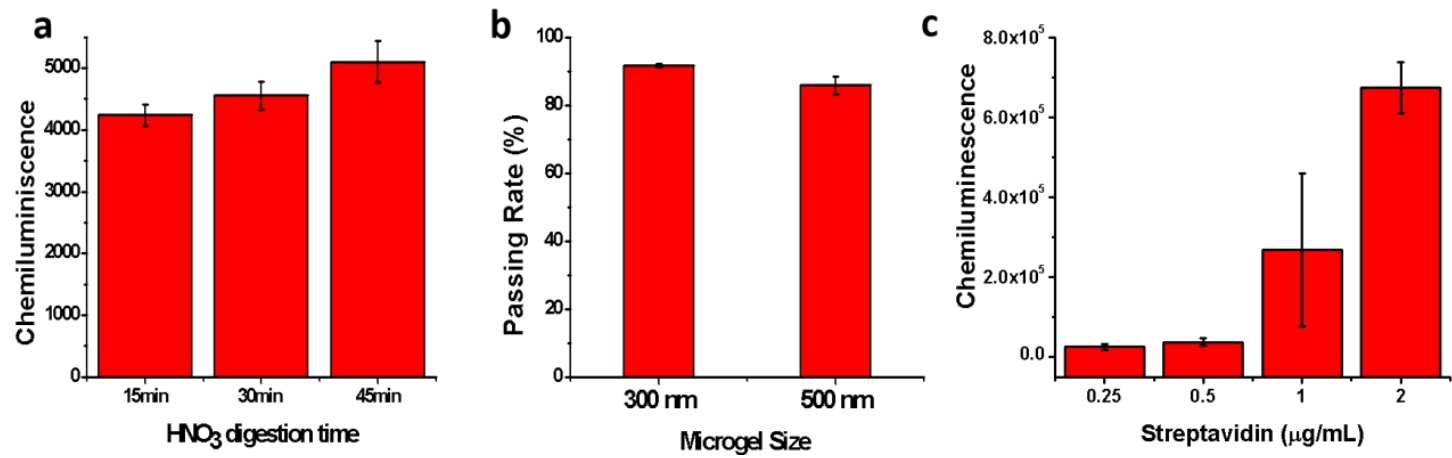
Figure S4. Quantification of EVs in serums from healthy donor and breast cancer patient. With the calibration curve prepared by serial dilution of the lyophilized EVs from COLO 1 cell line (HansaBioMed Life Sciences), we can also obtain the concentration of EVs present in the serum samples. It turns out that, in the $100 \mathrm{X}$ diluted serum, the concentration of the CD63-positive EVs was about $6.92 \pm 0.27 \times 10^{9}$ $\mathrm{EVs} / \mathrm{mL}$ while that of the HER2-positive EVs being comparable to the background signal in the serum from the healthy individual. In the serum sample from the cancer patient, the CD63- and HER2-positive EVs were found to be about $2.00 \pm 0.03 \times 10^{4}$, and $6.17 \pm 0.22 \times 10^{5}$, respectively.

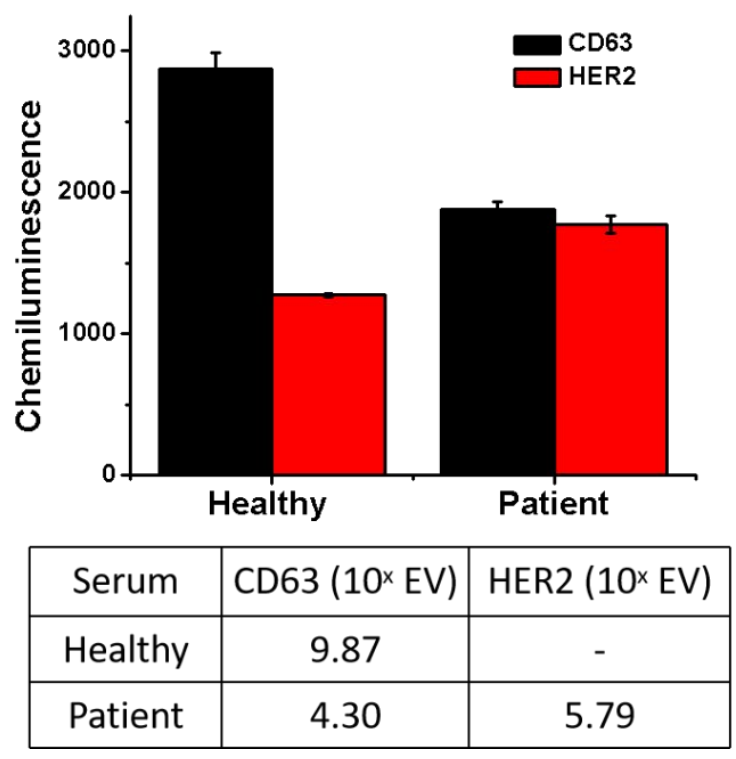


Figure S5. Schematic illustration of traditional ultracentrifugation-based method (a) and our method (b) for EV quantification.

a

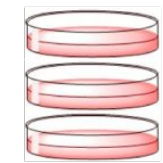

$150 \mathrm{~mm}$ dish $(25 \mathrm{ml}$ cell culture medium) $2.0+/-0.7 \times 10^{7}$ cells

b

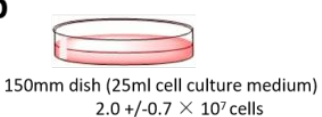
$2.0+/-0.7 \times 10^{7}$ cells
a
$75 \mathrm{ml}$ culture media

cells were cultured in triplicated

75 micell culture met was used for EV extraction

$500 \mathrm{~g} \times 15$ minutes $15,000 \mathrm{~g} \times 20$ minutes

$110,000 \mathrm{~g} \times 70$ minutes

wash with $1 \times$ DPBS $110,000 \mathrm{~g} \times 70$ minutes

Pellet $=200$ ul EV ( $10^{10}-10^{11}$ Particles $/ \mathrm{mL}$ ) NTA ELISA

Figure S6. Detection of EVs and free CD63 protein by CuS-MG.

$0.1 \mathrm{ml}$ cell culture media was used for EV extraction

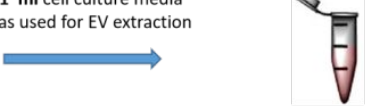

our assay

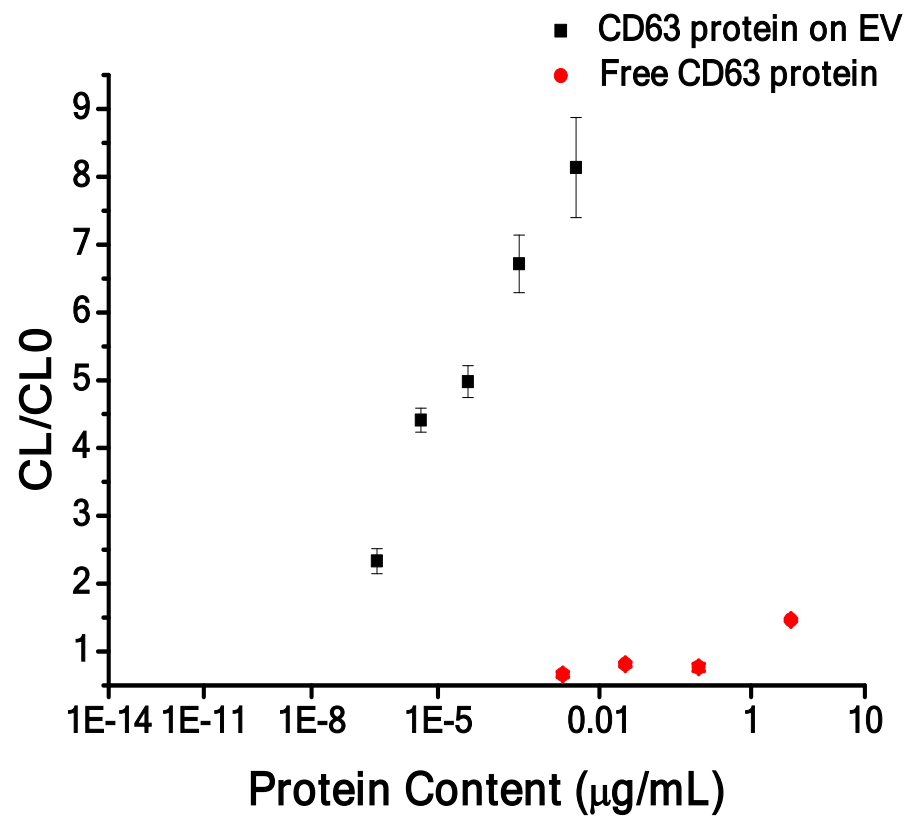




\section{Supporting Tables}

Table S1. Fabrication conditions of three sized microgels.

\begin{tabular}{|c|c|c|c|c|}
\hline Microgel Name & Size (nm) & Recipe & Bis (\%) & ALA adding time \\
\hline $100 \mathrm{~nm}$ & $83.2 \pm 16.1$ & $\begin{array}{l}\text { NIPAM: } 0.152 \mathrm{~g} \\
\text { Bis: } 0.030 \mathrm{~g} \\
\text { SDS: } 0.045 \mathrm{~g} \\
\text { AA: } 0.048 \mathrm{~g} \\
\text { KPS: } 0.02 \mathrm{~g} \\
\text { ALA: } 0.035 \mathrm{~g}\end{array}$ & . & 10 mins \\
\hline $300 \mathrm{~nm}$ & $305.0 \pm 22.7$ & $\begin{array}{l}\text { NIPAM: } 0.152 \mathrm{~g} \\
\text { Bis: } 0.020 \mathrm{~g} \\
\text { SDS: } 0.0225 \mathrm{~g} \\
\text { AA: } 0.048 \mathrm{~g} \\
\text { KPS: } 0.005 \mathrm{~g} \\
\text { ALA: } 0.035 \mathrm{~g}\end{array}$ & 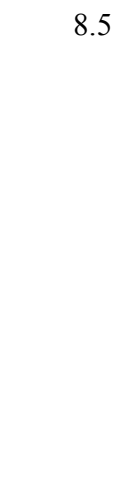 & 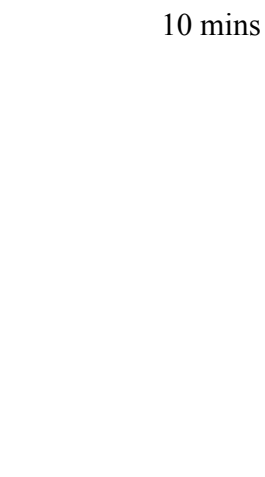 \\
\hline $500 \mathrm{~nm}$ & $539.8 \pm 35.6$ & $\begin{array}{l}\text { NIPAM: } 0.152 \mathrm{~g} \\
\text { Bis: } 0.020 \mathrm{~g} \\
\text { SDS: } 0.0225 \mathrm{~g} \\
\text { AA: } 0.048 \mathrm{~g} \\
\text { KPS: } 0.005 \mathrm{~g} \\
\text { ALA: } 0.035 \mathrm{~g}\end{array}$ & 8.5 & 60 mins \\
\hline
\end{tabular}


Table S2. Comparison of our methods with reported methods.

\begin{tabular}{|c|c|c|c|}
\hline Method & $\begin{array}{l}\text { LOD } \\
\text { (particles } / \mu \mathrm{L})\end{array}$ & $\begin{array}{l}\text { Linear Range } \\
\text { (particles } / \mu \mathrm{L} \text { ) }\end{array}$ & Reference \\
\hline Electrochemical immunosensor & 200 & $10^{2}-10^{6}$ & 12 \\
\hline Integrated magneto-electrochemical sensor & $1 \times 10^{4}$ & $10^{4}-10^{7}$ & 25 \\
\hline Size Exclusion chromatography & $3.9 \times 10^{4}$ & $1 \times 10^{5}-1.5 \times 10^{6}$ & 26 \\
\hline Microfluidic analysis & 50 & $10^{2}-10^{6}$ & 27 \\
\hline Bivalent-Cholesterol-Labeled DNA & $2.2 \times 10^{3}$ & $\sim 10^{3}-10^{5}$ & 28 \\
\hline Electrochemical Detection & 20 & $10^{1}-10^{9}$ & 29 \\
\hline Graphitic Carbon Nitride Nanosheets & $1.3 \times 10^{5}$ & $1.9 \times 10^{6}-3.4 \times 10^{7}$ & 30 \\
\hline DNA-capped single-walled carbon nanotubes & $5.2 \times 10^{5}$ & $1.8 \times 10^{6}-2.2 \times 10^{7}$ & 31 \\
\hline Electrochemical Detection & 70 & $10^{3}-10^{5}$ & 32 \\
\hline Copper-Mediated Signal Amplification & $4.8 \times 10^{4}$ & $7.5 \times 10^{4}-1.5 \times 10^{7}$ & 33 \\
\hline Magnetic-Based Microfluidic Device & $4.4 \times 10^{3}$ & $7.6 \times 10^{4}-7.6 \times 10^{8}$ & 13 \\
\hline Aptamer based amplification & $1.16 \times 10^{3}$ & $1.75 \times 10^{3}-7.0 \times 10^{6}$ & 34 \\
\hline gold-loaded ferric oxide nanocubes & $1 \times 10^{3}$ & $10^{3}-10^{7}$ & 35 \\
\hline
\end{tabular}

